(6\%), vertical fractures (5\%), horizontal fractures (5\%) and other pathologies.

In $58 \%$ of cases an extraction was performed, in $6 \%$ a scale and root planing of the pathological area and in $10 \%$ of cases only pharmacological treatment was indicated. Other procedures performed were first stage of root canal treatment, root canal treatments of monoradicular teeth, cementing fixed dentures and removal or repair of orthodontic appliances. Only three patients were referred to emergency hospital services. An estimated $80 \%$ of treatments provided a permanent resolution of the pathology and in the remaining cases it was possible to offer a partial or temporary solution.

In conclusion, the urgent dental care provided was undoubtedly strenuous, but it was also a source of great satisfaction for the dentist, both personally and professionally. Moreover, the patients greatly appreciated his degree of availability and the importance of the work achieved. After this period the dentist was tested for SARS-COV-2 antibodies and a negative result was received.

L. Varela-Montes, R. Gómez de Diego, M. Varela Morales, Madrid, Spain https://doi.org/10.1038/s41415-020-1730-4

\section{Skill mix alive and well}

Sir, your correspondent E. Gordon (The end of skill mix; BDJ 2020; 228: 655) derides the term 'skill mix' as 'an egalitarian fantasy supported only by salaried academic elites'.

The existence of Gateway Dental Practice in Abergavenny, which became an Employee Owned Trust (similar to the John Lewis Partnership) in October 2016, contradicts this view. This innovative dental practice ownership model is doing its part in building a motivated and sustainable dental workforce. In addition to promoting skill mix, the model also promotes social sustainability in its ethos of collaborative working, alongside the encouragement of entrepreneurial activity, training and development for the employees. It reflects the fact that dental practices are assets to the communities they serve, such as in providing employment opportunities to local residents, as well as providing vital healthcare services. I encourage practice owners considering disposal of their practices to read the recent paper by Allen and Karki. ${ }^{1}$

I would agree, however, that there is a need for regulatory reform, both to bolster skill mix throughout dental practices and to improve access for those in need. The COVID-19 pandemic is stimulating contract reform significantly throughout the UK, with commissioners of dental services having to re-evaluate provision and monitoring.

\section{H. Hutchison, Abergavenny, UK}

\section{Reference}

1. Allen M, Karki A. Employee Owned Enterprise - an innovative general dental practice model. BDJ In Practice 2020; 33: 20-23.

\section{https://doi.org/10.1038/s41415-020-1731-3}

\section{Loss of taste and smell}

Sir, on 26 April 2020, the US Centers for Disease Control and Prevention included 'New loss of taste (dysgeusia/ageusia) and smell (anosmia/hyposmia)' in its list of symptoms of COVID-19 disease. ${ }^{1}$

In the absence of any comprehensive analysis of the subject, we reviewed the published literature on COVID-19 associated early dysgeusia and anosmia, finding a total of five studies from the European community, China, Italy, USA, and Iran. ${ }^{2,3,4,5,6}$ These yielded a total of 10,847 COVID-19 patients; 8,816 (81.27\%), and 8,119 (74.85\%) presented with/developed dysgeusia and/or anosmia, respectively indicating these symptoms in almost three-quarters of COVID-19 patients.

However, there are knowledge gaps. The simultaneous presence of both symptoms in the prodromal or presenting stages of COVID-19 is unclear as is the temporal association of these with other critical symptoms. Some described anosmia prior to hospitalisation followed by symptoms of dysgeusia afterwards, and others the reverse. Also, the question of how long before the definitive early symptoms of COVID-19 such as fever, sore throat, etc does dysgeusia and/or anosmia appear, particularly in otherwise asymptomatic ambulatory patients, is unresolved.

If these two symptoms were relatively reliable harbingers of COVID-19, then there are multiple clinical, community interventional strategy and disease spread implications. Both are simple for self-awareness and without medical consultation could enormously expedite self- or tele-diagnosis of COVID-19. This would be particularly pertinent in overcrowded and resource-meagre communities in the developing world, and in refugee camps. In the event, community education of these symptoms through media broadcasts, leaflets, and public notices could significantly reduce the disease spread and burden. Finally, if dysgeusia and anosmia were reliable and valid premonitory symptoms of the disease, then dental, medical and para-medical services may in future include a question on the acute loss of taste and smell in all pre-treatment patient history questionnaires so as to diagnose potential, or otherwise asymptomatic, COVID-19 patients.

L. Samaranayake, K. Sadir Fakhruddin, C. Panduwawala, Sharjah, United Arab Emirates

\section{References}

1. The National Law Review. CDC Adds New Symptoms for COVID-19 Screening - Employers Must Adjust Accordingly. 27 April 2020. Available at: https://www. natlawreview.com/article/cdc-adds-new-symptomscovid-19-screening-employers-must-adjust-accordingly (accessed 30 May 2020)

2. Lechien J R, Chiesa-Estomba C M, De Siati D R et al. Olfactory and gustatory dysfunctions as a clinical presentation of mild-to-moderate forms of the coronavirus disease (COVID-19): a multi-center European study. Eur Arch Otorhinolaryngol 2020; doi: 10.1007/ s00405-020-05965-1.

3. Giacomelli A, Pezzati L, Conti F et al. Self-reported olfactory and taste disorders in SARS-CoV-2 patients: a cross-sectional study. Clin Infect Dis 2020; doi: 10.1093/ cid/ciaa330.

4. Mao L, Jin H, Wang M et al. Neurologic manifestations of hospitalized patients with Coronavirus Disease 2019 in Wuhan, China. JAMA Neurol 2020; doi: 10.1001/ jamaneurol.2020.1127.

5. Yan C H, Faraji F, Prajapati D P, Boone C E, DeConde A S Association of chemosensory dysfunction and Covid-19 in patients presenting with influenza-like symptoms. Int Forum Allergy Rhinol 2020; doi: 10.1002/alr.22579.

6. Bagheri SH R, Asghari A M, Farhadi M et al. Coincidence of COVID-19 epidemic and olfactory dysfunction outbreak. medRxiv 2020; doi: https://doi.org/10.1101/2020.03.23. 20041889.

https://doi.org/10.1038/s41415-020-1732-2

\section{Virus-spreading procedures}

Sir, the current pandemic highlights the need to consider alternative evidence-based treatments that involve no virus-spreading procedures to prevent transmission. For example, non-cavitated dental caries lesions involving up to outer third of dentine can be managed by preventive measures including fissure sealant and proximal sealing, with minimal risk of aerosol production. ${ }^{1}$ Cavitated shallow to deep carious lesions that do not involve pulp can be managed using selective caries removal and atraumatic restorative treatment (ART), without the use of rotary instruments. ${ }^{2,3}$ Heavily broken-down teeth can be temporarily restored by using stainless steel crowns with no preparation required. ${ }^{4}$ Minimally invasive endodontic treatments 